\title{
THE EFFECTS OF NEONATAL ASPHYXIA ON PHYSICAL AND MENTAL DEVELOPMENT
}

BY

\author{
W. A. B. CAMPBELL, E. A. CHEESEMAN, and ANNE W. KILPATRICK \\ From the Departments of Child Health and of Social and Preventive Medicine, the Queen's \\ University of Belfast, and the Royal Maternity Hospital, Belfast
}

(Received for Pubucation January 25, 1950)

This short paper describes a study of the development of children who suffered severe delay in establishing normal respiration at birth. Their progress has been measured against that of children who escaped this initial handicap, but who are in most other respects similar. We have not been concerned here with the immediate effects of asphyxia neonatorum, but with the effects, if any, some eight to 11 years after birth.

Most of the existing work on this subject has been carried out retrospectively. That is, the data usually consist of a group of children known to be mentally or physically retarded; the individual birth histories of the group are traced, and from the histories an estimate is made of the proportion of retarded children who had suffered from delayed respiration at birth. This method, although it sometimes offers very suggestive evidence that asphyxia in the paranatal period does leave permanent sequelae, cannot give any help in assessing the prognosis for a group of ' asphyxiated' children. Moreover, it is open to the objection that in some cases the mother's description of her infant's condition at birth is the only available history; after a lapse of years this may be inaccurate or unconsciously coloured by her endeavours to find some cause for her child's departure from the normal. Smith (1948) draws attention to these difficulties and points out that 'we still lack data from which a prognosis can be given in the individual infant.'

Much has been written on the birth history of children who in later life show behaviour problems or similar psychological disturbance. Despert (1946)

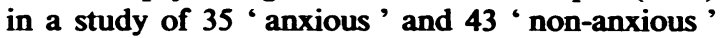
children included asphyxia among unfavourable birth conditions which "were considered an important contributing factor in the genesis of anxiety in young children.' Schreiber (1938) found a history of 'apnoea' in $\mathbf{7 0} \%$ of $\mathbf{5 0 0}$ children referred to his clinic on account of neurological disorders, but Galloway (1938), in discussing this work of Schreiber, comments pertinently that the apnoea at birth may be, at least partly, the result of some congenital neurological disorder. Some years later Schreiber (1943) investigated 146 patients who had low intelligence quotients seen consecutively at psychiatric clinics; only patients whose birth histories were available in one of the local hospitals were included. On account of a family history of mental defect or post-natal factors, 46 patients were discarded and the remaining 100 were compared with 100 control children of comparable background, but with high intelligence quotients. He found that $24 \%$ of the low intelligence group and only $6 \%$ of the high intelligence group experienced apnoea at birth and, further, that $39 \%$ of the former compared with $27 \%$ of the latter group required operative interference. He suggested that there is a relationship between the presence of apnoea at birth, from whatever cause, and subnormal intelligence.

From 673 children with behaviour problems, Rosenfeld and Bradley (1948) selected groups of 126 children who had had pertussis, 28 with neonatal asphyxia and 100 with neither a history of pertussis nor of neonatal asphyxia. How the last group, which served as controls, was selected, is not very clear. All the children were of normal or superior intelligence. Each of the six presenting symptoms was one and a half times as frequent in the pertussis and asphyxia groups as in the control group. The syndrome of five or six of these symptoms was eight times as frequent in the pertussis and asphyxia groups as in the controls. Again Smith (1948) points out that no asphyxiated infant who later showed a normal development would be traced by this type of investigation.

Preston (1945), discussing the records of 132 patients of a psychiatric clinic who were selected on account of difficulty at birth, makes the point that asphyxia may be entirely pre-natal, and that a normal appearance at birth does not eliminate the possibility of mental damage in later life resulting from such pre-natal asphyxia.

Courville and Marsh (1944) studied the effects of 
neonatal asphyxia by pneumoencephalography and histological examination of cases showing " the wellknown symptom-complexes of mental deficiency, hemiplegia, athetosis, convulsions, or various combinations.' They concluded that conditions such as microgyria, porencephaly, and atrophic lateral sclerosis were present, and suggested that these apparently diverse changes might all be due to the effects of asphyxia.

Windle and his colleagues (Windle and Becker, 1943; Windle, Becker, and Weil, 1944; Windle, 1944) have produced microscopic changes in the brain of guinea-pigs subjected to varying degrees of asphyxia and have also demonstrated behaviour changes in the animals that survived.

Not only cases of psychiatric abnormality have been investigated in this way. Evans (1948), in a series of 114 individuals with cerebral palsy, found that asphyxia, together with such factors as forceps delivery or obstetric analgesia, was commonly found in the athetoid group. He suggests a causal relationship.

Comparatively few investigations have been carried out with the preferable approach of following up a series of ' asphyxiated' infants and comparing them with 'non-asphyxiated' controls. McPhail and Hall (1941) analysed the factors responsible for delayed respiration in a series of 1,002 deliveries. They found 'severe apnoea' present in 6\%. Their definition of severe apnoea included all cases where breathing and crying were delayed for more than one minute, and all cases showing cyanosis at any time during the first few days. They then attempted to follow up 861 consecutively born infants; unfortunately only $\mathbf{2 7 0}$ of these were traced and were given an intelligence test and a behaviour rating. They found no significant difference in the results obtained for 34 infants classed as 'asphyxiated,' compared with the group as a whole. They concluded that neonatal apnoea need not cause permanent damage to the brain provided that, as was their practice, adequate oxygen is administered during the apnoeic period.

Stevenson (1948) followed up 226 unselected children for five to eight years. At birth they had been divided into two groups - ' good' and 'poor' -by physical assessment. The poor group included, among other factors, resuscitation and delayed onset of respiration and cyanosis. Of the poor group, $39 \%$ were maladjusted, compared with $19 \%$ of the good group.

Darke (1944) selected 49 cases of severe neonatal asphyxia from 25,261 deliveries. He included all infants with asphyxia pallida and those who were definitely apnoeic for three minutes or more. He was only able to trace 19 of these after four to
12 years; the intelligence quotients of 17 of these were below those of parents or sibs used as controls.

\section{Examination Procedure}

For the present enquiry an examination was made of the case histories of all infants born in the Royal Maternity Hospital, Belfast, during the years 1938 to 1941 , inclusive, a total of 6,009 live births. Since the purpose of the investigation was to ascertain the remote prognosis of asphyxia at birth, neonatal deaths, in so far as they were known, were not included. All cases with one of the following criteria were selected for study: (1) Asphyxia pallida; (2) asphyxia livida lasting for a stated period of over two minutes.

Birth records are filed in the hospital in chronological order, and infants were selected for a control series by including the records which were filed immediately before and immediately after each ' asphyxia' record. All records on which there were vague terms such as 'cyanosed' or 'blue asphyxia,' with no further information, were excluded from both groups. This process resulted in a group of 89 ' asphyxiated' infants and 178 controls. It was considered impracticable to extend the series by including births before 1938 or after 1941, since, in the first instance, records were maintained differently before 1938 , and in the second, examinations of children of 6 years of age and younger would have been incurred. We wished to avoid the examination of such young children because of the difficulty in applying the intelligence tests.

A circular letter was sent out in batches of ten to parents of the selected children. The letter explained simply and briefly the purpose of the investigation and asked the mother if she would bring her child to the hospital for examination on a stated day. If she was unable to come on the day suggested, or if the letter was returned by the postal authorities owing to a change of address, a personal visit was made to arrange another appointment or to try to ascertain the family's present location. As might be expected, many families had moved several times, and in some cases whole streets had been destroyed by enemy action, consequently, several visits were necessary to trace some children.

Of the 267 children whose names were originally drawn from the hospital records, 195 , or $73 \%$, were ultimately examined. Of the 72 unexamined children, seven were known to have died, two were mentally deficient and could not be examined, and the parents of a further 18 refused to cooperate in the survey, although repeated attempts were made to persuade them. All efforts to trace the remaining 
45 children failed. The position is summarized for the two groups separately in Table 1.

TABuE 1

RELATION OF 195 CHILDREN EXAMINED TO 267 ORIGINALIY SELECTED FROM THE RECORDS

\begin{tabular}{|c|c|c|c|}
\hline & $\begin{array}{l}\text { Asphyxia } \\
\text { Group }\end{array}$ & $\begin{array}{l}\text { Control } \\
\text { Group }\end{array}$ & Total \\
\hline $\begin{array}{l}\text { Number of children ex- } \\
\text { amined } \ldots \\
\text { Number not examined: } \\
\text { died } \ldots \\
\text { mentally deficient } \\
\text { refused to cooperate } \\
\text { not traced } \ldots\end{array}$ & $\left.\begin{array}{r}2 \\
2 \\
4 \\
20\end{array}\right\} 28$ & $\left.\begin{array}{c}5 \\
- \\
25\end{array}\right\} 44$ & $\left.\begin{array}{r}195 \\
7 \\
2 \\
18 \\
45\end{array}\right\} 72$ \\
\hline $\begin{array}{l}\text { Number of children selected } \\
\text { from records .. }\end{array}$ & 89 & 178 & 267 \\
\hline
\end{tabular}

The percentage of children actually traced $(83 \%)$ and examined $(73 \%$ is considered to be higher than that usually achieved in most similar series. This is probably due to the self-contained nature of the population, the limited area of Northern Ireland, and the interest which members of the community take in matters of health. The longest journey necessary for any child and parent who attended was 70 miles, and the longest journey made to trace a family was $\mathbf{5 0}$ miles; the majority of the children examined lived within 10 miles of Belfast, and most of the untraced families were known to have left Northern Ireland.

The investigation was arranged so that at each examination session, neither of the clinicians (W.A.B.C. or A.W.K.) knew the group (asphyxia or control) to which any individual child belonged. Doubtful physical findings were checked by both examiners to ensure agreement. For each child, height, weight, chest circumference and expansion were recorded, and a general clinical examination followed.

BLood ANalysis. After the general clinical examination $2 \mathrm{ml}$. of venous blood were taken into a bottle containing Wintrobe's anti-coagulant and within 48 hours the haemoglobin content of the blood was estimated as follows: $0.05 \mathrm{ml}$. of blood was drawn into a pipette and transferred to a test tube containing 5 $\mathrm{ml}$. of $\mathrm{N} / 10 \mathrm{NaOH}$. This was allowed to stand for five minutes, boiled in a water bath for five minutes and then cooled. The alkaline haematin content was then estimated by means of a 'biochem' absorptiometer, calibrated with the Gibson-Harrison (1945) standard $(100 \%=14 \cdot 8 \mathrm{~g})$.
The examination session was concluded by the children present carrying out the group test version of Raven's matrices (1938). No time limit was imposed. An individual test for each child might have had some advantages, but it would not have been possible to arrange this. On the other hand, it seemed that the test used was the most suitable for children of these ages (8 to 11 years) and it had the added advantage of being different from the tests which are extensively used in the primary schools as a preparation for the qualifying examination.

\section{Completeness of the Data}

Owing to the fact that $27 \%$ of the original sample of 267 infants were not examined, the actual results obtained for either group are not necessarily representative of all the ' asphyxiated' children (89) and control children (178) born in the hospital in the years 1938-41. Consequently it must be admitted at once that the incomplete samples used cannot be a basis for a firm and final conclusion.

However, the comparison between the control and the 'asphyxia' group is likely to be biased, only if the unexamined members of either or both groups represent a biased sample of the whole series. Since birth records are available for all 267 children, we have been able partially to examine this possibility.

Between the examined group (195 children) and the unexamined group (72 children) no significant difference was found in the proportion of ' asphyxiated' births, the distributions of year of birth, sex, order of birth, gestation period of mother, type of presentation or delivery at birth, or in the mean birth weights. On the other hand, the mean age at time of confinement of mothers of examined children (28.6 years) was just significantly older than the corresponding mean age of mothers of unexamined children (26.8 years). (Difference = 1.8 years, $t=1.98$, degrees of freedom $=260$ and $0.05>P>0.01$.) Five ages were not recorded in the original records, but these omissions are unlikely to affect materially this comparison.

This series of tests demonstrates the similarity between the two groups of children at birth. The small difference in the mean age of the mother at confinement, we feel, can be discounted, since there would be greater likelihood of younger families moving away from the Belfast area than there would be for older families. Therefore although we cannot with certainty prove that no bias exists in our later comparisons, no evidence of the possible existence of such bias has been forthcoming from the somewhat rigorous examination of all the available facts. 
Results

Preliminary Considerations. When any two groups of individuals are compared to trace the effects of a specific condition common to all members of one group and absent from all members of the other, it is essential that basically the two groups should be comparable in all other respects. Data collected in the manner of the present enquiry seldom, if ever, approximate to such ideals. It is, therefore, necessary to ascertain relevant basic differences between the groups and to make due allowance for them in the ultimate comparisons. From the original birth records we have been able to compare the 61 examined children in the asphyxia group with the 134 examined children in the control group in respect of (a) sex distribution, (b) distribution by order of birth, $(c)$ distribution by gestation period of mother, $(d)$ proportion of children breast fed for any length of time, (e) mean period of breast feeding, $(f)$ mean age of mother at confinement, $(g)$ distribution by year of birth, $(h)$ mean age of children, $(j)$ proportion of vertex presentations, $(k)$ proportion of normal deliveries, and $(l)$ mean birth weight of infant.

In all except the last three conditions, no significant difference was observed between the ' asphyxia' group and the control group. Of the ' asphyxia' group, 83.6\% were vertex presentations at birth, compared with $96.2 \%$ in the control group: the difference, $12.6 \%$, is significant $\left(\chi^{2}=15 \cdot 20\right.$, degrees of freedom $=1$, and $\left.P<0 \cdot 001\right)$. Of the ' asphyxia' births, $57.4 \%$ were classified as normal deliveries, compared with $84.3 \%$ of the control group: this difference $(26.9 \%)$ is also greater than could easily have arisen by chance $\left(\chi^{2}=7 \cdot 77\right.$, degrees of freedom $=1$, and $0.01>P>0.001)$.

The mean birth weight of the 'asphyxia' group was $108 \mathrm{oz}$. compared with a control group mean of $117 \mathrm{oz}$. The difference of $9 \mathrm{oz}$. is significant $(t=2 \cdot 85$, degrees of freedom $=193$, and $0.01>P>0.001$ ).

The difference in presentation and delivery for the two groups is probably associated with the actual birth condition of asphyxia neonatorum, but as the aetiology of this condition is outside the scope of this investigation, we are not specifically concerned with these factors. In themselves, the differences between the two groups in presentation and delivery are unlikely to have any bearing on examinations some eight to eleven years later, and we feel that such differences as have been observed can be ignored in later comparisons and be regarded as wholly associated with the condition of asphyxia.

The difference between the two mean birth weights is of more importance. Illingworth, Harvey, and Shan-Yah Gin (1949) have demonstrated the association between birth weight and later physical measurements. Consequently, if such association exists in the present data, allowance must be made for the influence of the different birth weights of the two groups upon the physical measurements ultimately compared. By so doing, we should at the same time allow for any possible preponderance of prematurely born children in either group, the existence of which seems unlikely from the examination of lengths of pregnancies, but which is a possibility when prematurity is assessed in terms of birth weight.

The statistical technique of covariance analysis (Fisher, 1946; Snedecor, 1946) enables us to make due allowance for the concomitant effect of birth weight, and at the same time a more precise test of significance can be applied if we take into account the further concomitant effect of age on physical measurement, even though the two groups do not differ in their mean ages. Therefore in Table 3 are shown the observed mean physical measurements, together with the means adjusted or corrected to a common mean birth weight and age for both the ' asphyxia' and the control groups. In each case, the appropriate tests of significance between the mean physical measurements of the two groups are given.

The homogeneity of each group of children has been examined for each of the variables studied. This was done by sub-dividing each group into four sub-groups: first born males, first born females, second and later born males, and second and later born females. It was considered that birth order and sex were the most likely factors to cause differences within either of the two main groups, 'asphyxia' or controls, of children. For each group the significance of the difference of the sub-group means of each studied variable was examined.

Physical Measurements. The sizes of the multiple correlation coefficients of the physical measurements on age and birth weight (Table 2) are such that it

TABLE 2

Multiple Correlation Coefficients of Physical Measurements on Age and Birth Weights

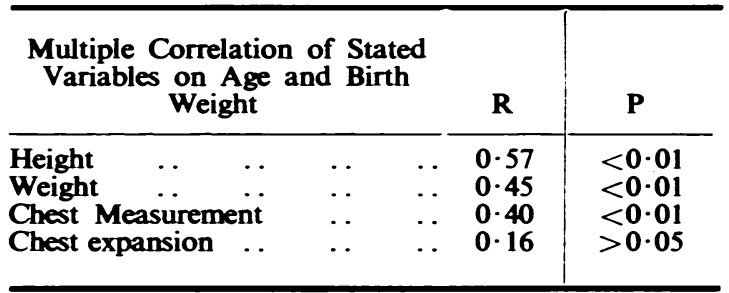

Degrees of freedom $=191$ 
appeared to be necessary to take the latter variables into account when comparing mean heights, weights, and chest measurements between different groups of children. The coefficient for chest expansion on age and birth weight was just insignificant at the $5 \%$ level, but in the interests of uniformity, the means of all the physical measurements have been corrected for the concomitant effect of age and birth weight.

Both the ' asphyxia' group and the control group can be considered as homogeneous in so far as height, weight, and chest expansion are concerned. For each, no significant difference was found between the four component sub-group means either before or after correction for age and birth weight.

On the other hand, the data of chest measurement revealed several inconsistencies in the control group, although the 'asphyxia' group appeared to be homogeneous. For the control group, the analysis of variance between the crude means of the four component sub-groups gave a significant variance ratio of $2.96\left(n_{1}=3, n_{2}=130\right.$ and $\left.0.05>P>0.01\right)$. When each sex was considered separately, no significant difference occurred between the birth rank groups of either sex. However, after correction for age and birth weight, it became apparent that the male data of chest measurement could not be considered as homogeneous, since the difference between the adjusted means of the birth order groups for males was significant $(t=2 \cdot 09$, degrees of freedom $=64$ and $0.05>P>0.02$ ). No significant difference was found between the adjusted sub-group means of the females. We therefore decided to make the ultimate comparison of chest measurement between the 'asphyxia' and the control group in terms of first born males, later born males and all females separately. Although the presentation of the results is somewhat handicapped by this procedure and the numbers of observations in the compared groups is reduced, any other method of grouping the data might give rise to spurious conclusions.

The comparisons between the 'asphyxia' and the control groups are shown in Table 3 for height, weight and chest expansion, and in Table 4 for chest measurement. The crude and the corrected means are shown in each case. No significant differences occurred in either the crude or the corrected means of height, weight or chest expansion, and in each case the differences were relatively small. Furthermore, no consistent excess in favour of either the ' asphyxia' or the control group occurred.

No significant difference occurred between the mean chest measurements (Table 4) of the females or the second and later birth rank group of the males.
This was also true after the means were adjusted to a common age and birth weight. With the first order birth group of males, a significant difference did occur and the control group had the greater mean chest measurement. A careful examination of the original chest measurements gave no useful pointer as to the reason for this significant difference. Apart from the fact that we may have been unlucky in the sampling of this particular variable, no reasonable theory can be advanced for this apparent difference between the results obtained for first born males and for other children.

Haenoglobin Estimations. In these data, the multiple correlation of the haemoglobin level on age and birth weight is very small and insignificant $(R=0.09$, degrees of freedom $=191$, and $P>0.05)$, and after some further consideration of the data it was decided that no useful purpose would be served by correcting the haemoglobin levels for age and birth weight. All comparisons between groups are therefore made in terms of the unadjusted means.

A preliminary examination of the data in each group revealed a heterogeneity in the four sub-group means of the control group data (variance ratio $=2 \cdot 71, n_{1}=3, n_{2}=130$, and $\left.0.05>P>0.01\right)$. This appeared to be due to a difference in mean haemoglobin level between the sexes, and further examination revealed that in both males and females no significant difference occurred between the mean haemoglobin levels of children of different rank of birth. It was therefore decided to compare the 'asphyxia' and control groups for each sex separately and the results are set out in Table 5 .

The difference between the haemoglobin level of the 'asphyxia' and the control group was negligible in the males, and although it was somewhat larger in the females, the difference was still insignificant. In each case the 'asphyxia' group had the higher mean haemoglobin level, but as the excesses could easily have arisen by chance, it is unlikely that the consistency of result is of any importance.

Intelligence Tests. The intelligence test was not carried out on one member of the control group, as the parent had to leave the hospital before the examination session ended; the comparison is therefore based on 61 'asphyxiated' children and 133 controls. Table 6 sets out the distribution of the children into Raven's (1938) five suggested grades.

An examination of the percentage distributions of this table does suggest that in the highest (I and II combined) and lowest (IV and V combined) intellectual grades, there is a relative preponderance of children in the 'asphyxia' group. These differences, however, are far from significant $\left(\chi^{2}=2 \cdot 21\right.$, degrees of freedom $=3$, and 0.7 $\left.>P>0 \cdot 5\right)$. 
TABuE 3

Comparison between Mean Heghts, Weghts, and Chest Expanshon of asphyxia and Control Groups

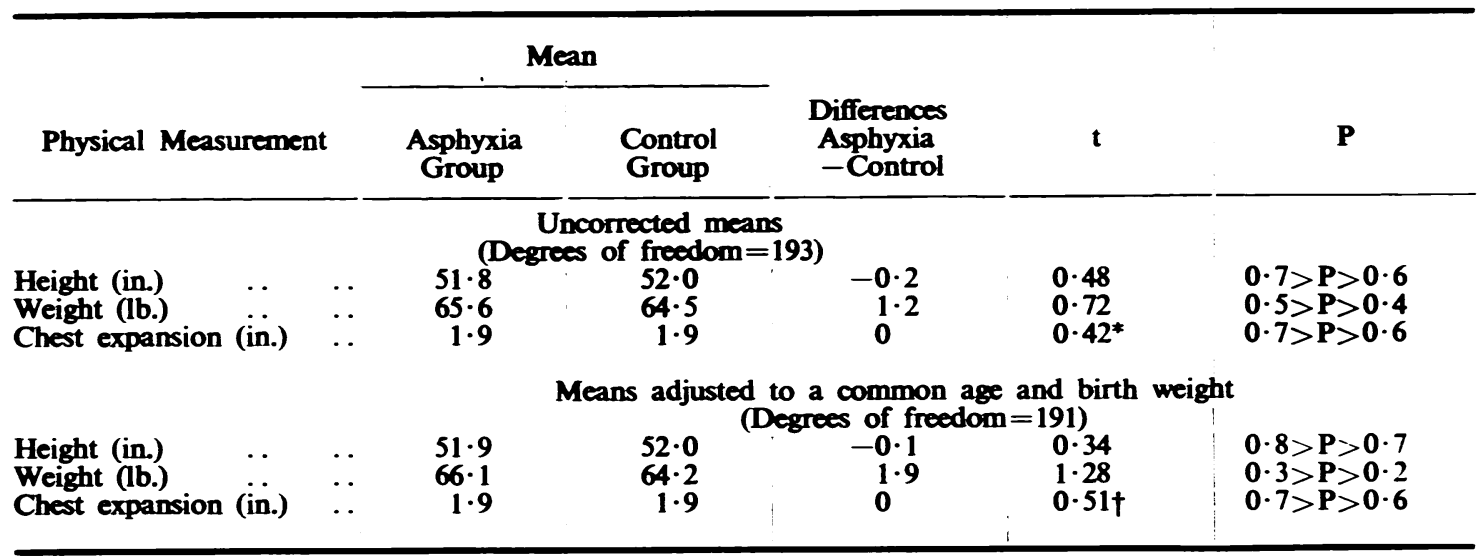

- Calculated on difference of -0.04 inches before approximation of means to first place of decimals.

+ Calculated on difference of -0.05 inches.

TABLE 4

Comparison between mean Chest Measuremients of asphyxia and Control Groups

\begin{tabular}{|c|c|c|c|c|c|c|}
\hline \multirow[b]{2}{*}{ Sub-group } & \multicolumn{2}{|c|}{$\begin{array}{l}\text { Mean Chest } \\
\text { Measurement (in.) }\end{array}$} & \multirow{2}{*}{$\begin{array}{c}\text { Differences } \\
\text { Asphyxia } \\
\text {-Control }\end{array}$} & \multirow[b]{2}{*}{$\mathbf{t}$} & \multirow[b]{2}{*}{$\begin{array}{l}\text { Degrees } \\
\text { of } \\
\text { Freedom }\end{array}$} & \multirow[b]{2}{*}{$\mathbf{P}$} \\
\hline & $\begin{array}{l}\text { Asphyxia } \\
\text { Group }\end{array}$ & $\begin{array}{l}\text { Control } \\
\text { Group }\end{array}$ & & & & \\
\hline \multicolumn{7}{|c|}{ Uncorrected Means } \\
\hline \multirow{3}{*}{$\begin{array}{l}\text { Male first order births } \\
\text { Male second and later order } \\
\text { of birth } . \\
\text { Females, all orders of birth }\end{array}$} & $26 \cdot 1$ & $27 \cdot 1$ & -1.0 & $2 \cdot 67$ & 51 & $0.02>P>0.01$ \\
\hline & $26 \cdot 9$ & $26 \cdot 7$ & $0 \cdot 2$ & $0 \cdot 32$ & 40 & $0.8>P>0.7$ \\
\hline & & & & & & $00>1>02$ \\
\hline \multirow{3}{*}{$\begin{array}{l}\text { Male first order births } \\
\text { Male second and later order } \\
\text { of birth } . \\
\text { Females, all orders of birth }\end{array}$} & ${ }_{26 \cdot 3}^{\text {Mear }}$ & $\begin{array}{l}\text { adjusted tc } \\
26.9\end{array}$ & $\begin{array}{c}\text { common ag } \\
-0.6\end{array}$ & $\begin{array}{l}\text { and bi } \\
2 \cdot 03\end{array}$ & $\begin{array}{r}\text { weight } \\
49\end{array}$ & $0.05>P_{>}>0.02$ \\
\hline & $27 \cdot 1$ & $26 \cdot 6$ & 0.5 & 0.76 & 38 & $0.5>P>0.4$ \\
\hline & $26 \cdot 5$ & $26 \cdot 3$ & $0 \cdot 2$ & 0.90 & 96 & $0.4>P>0.3$ \\
\hline
\end{tabular}

TABLE 5

Comparison between Mean haemoglobin levels of Asphyxia and Control Groups

\begin{tabular}{|c|c|c|c|c|c|c|c|}
\hline \multirow[b]{2}{*}{ Sex } & \multicolumn{3}{|c|}{$\begin{array}{c}\text { Mean Haemoglobin } \\
\text { Level }(\%)\end{array}$} & \multirow{2}{*}{$\begin{array}{c}\text { Difference } \\
\text { Asphyxia } \\
\text {-Control }\end{array}$} & \multirow[b]{2}{*}{$\mathbf{t}$} & \multirow{2}{*}{$\begin{array}{c}\text { Degrees } \\
\text { of } \\
\text { Freedom }\end{array}$} & \multirow[b]{2}{*}{$\mathbf{P}$} \\
\hline & & $\begin{array}{l}\text { Asphyxia } \\
\text { Group }\end{array}$ & $\begin{array}{l}\text { Control } \\
\text { Group }\end{array}$ & & & & \\
\hline Males & .. & $90 \cdot 4$ & $90 \cdot 1$ & $0 \cdot 3$ & $0 \cdot 10$ & 93 & $P>0.9$ \\
\hline Females & . & $88 \cdot 7$ & $86 \cdot 0$ & $2 \cdot 7$ & $1 \cdot 38$ & 98 & $0.2>P>0.1$ \\
\hline
\end{tabular}


TABLE 6

Comparison of Distribution of INTElligence Quotients of AsphyXia and Control Groups

\begin{tabular}{rllllllll}
\hline \multicolumn{3}{c}{ Intelligence Quotient Group } & & \multicolumn{2}{c}{ Asphyxia } & Group & & \multicolumn{2}{c}{ Control Group } \\
\hline
\end{tabular}

The observed difference between the two distributions can certainly not be regarded as unusual.

No attempt has been made to express the results of the tests in intelligence quotients since this would have involved corrections for age in order to compare the two groups: to do this simply would involve assumptions which might not be justified (Raven, 1948). On the other hand, it has been suggested (Raven, 1947) that discrepancies of scores actually obtained from scores expected which exceed 2 units in any one of the five component sets of the matrix invalidate the use of an individual's total score as a 'consistent estimate of his general capacity for intellectual activity'. In our series such discrepancies occurred in the tests of 18 of the 'asphyxia' group and 40 of the control group, i.e. $30 \%$ of each group had total scores which might be unreliable. If these are omitted from the comparison, then the distributions are as in Table 7. The total effect of leaving out the unreliable scores is very slight when the revised 'asphyxia' and control distributions are compared. The chance of observing discrepancies as great or greater than those between the distributions of Table 7 is higher $\left(\chi^{2}=1 \cdot 06\right.$, degrees of freedom $=3$, and $\left.0 \cdot 8>P>0 \cdot 7\right)$ than it was in the case of Table 6, which included all tested children. We feel, therefore, that we can ignore the possibility of unreliable scores, in so far as the comparison of the two groups is concerned, particularly as Raven suggests that for general purposes the total scores can be used even when discrepancies, as defined above, occur.

Asher and Roberts (1949) found a lower mean birth weight among a sample of children attending special schools for educationally subnormal children than among normal children. If the association between intelligence and birth weight implied by this work exists for the present data it would seem reasonable to expect a larger proportion of children in the lower intellectual groups (IV and V) and a somewhat smaller proportion in the higher groups (I and II) in the 'asphyxia' group, than in the control group, since the former were significantly lighter in birth weight. Such, however, is not the case: $54.1 \%$ of the 'asphyxia' group, compared with $53.3 \%$ of the control group were classified as ' definitely below average intellectual capacity' or 'intellectually defective,' whereas $11.4 \%$ of the ' asphyxia' group, compared with $6.0 \%$ of the control group, were classified as 'intellectually superior' or 'definitely above average intellectual capacity' (Table 6). If anything, the advantage

TABLE 7

Comparison of Distribution of INTElligence Quotients of AsphyXia and Control Groups*

\begin{tabular}{|c|c|c|c|c|c|c|}
\hline \multicolumn{3}{|c|}{ Intelligence Quotient Group } & \multicolumn{2}{|c|}{ Asphyxia Group } & \multicolumn{2}{|c|}{ Control Group } \\
\hline & & & Number & Percentage & Number & Percentage \\
\hline \multirow[t]{2}{*}{$\begin{array}{l}\text { II } \\
\text { III } \\
\text { IV }\end{array}$} & 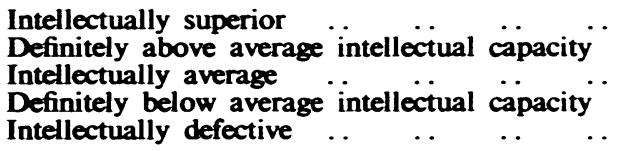 & $\begin{array}{l}\cdots \\
\cdots \\
\cdots \\
\cdots\end{array}$ & $\begin{array}{r}\overline{3} \\
12 \\
21 \\
7\end{array}$ & $\begin{array}{r}\overline{7} \cdot 0 \\
27 \cdot 9 \\
48 \cdot 8 \\
16 \cdot 3\end{array}$ & $\begin{array}{r}2 \\
2 \\
31 \\
40 \\
18\end{array}$ & $\begin{array}{r}2 \cdot 2 \\
2 \cdot 2 \\
33 \cdot 3 \\
43 \cdot 0 \\
19 \cdot 4\end{array}$ \\
\hline & & & 43 & $100 \cdot 0$ & 93 & $100 \cdot 1$ \\
\hline
\end{tabular}

- Omitting those with unreliable scores. 
lies with the 'asphyxia' group in the higher grades, though statistically the difference is not important. Thus, if a correction were necessary and possible for the effect of differing mean birth weights, it would seem reasonable to expect a still more favourable distribution for the 'asphyxia' group. In other words, if the difference in mean birth weights between the two groups does affect the comparison of their intelligence distributions, then the comparison of the observed distributions is likely to be a more exacting test of the intellectual capacities of the 'asphyxia' group than need legitimately be applied; even so, the data reveal no significant difference in the results of the matrix tests of the two groups. This conclusion would appear to be in agreement with that of McPhail and Hall (1941), although they were disposed to attribute the result not so much to the absence of after-effects of asphyxia neonatorum, as to the beneficial effects of administering oxygen in the apnoeic period.

Clinical Observations. Although having no bearing upon the main conclusions of this investigation, certain clinical observations were made which are of general interest.

In view of Evans' (1948) paper, it is interesting that the only two athetoid children in the series were both in the ' asphyxia ' group. One of these children (aged 10 years) was sufficiently normal in other respects to be completely examined and was included in the investigation. She was undersized, with very poor chest expansion (half inch); her haemoglobin level was $74 \%$ and below the average; her score in the matrix test was 13 , corresponding to the 5 percentile point for children of her age. The other athetoid child was mentally deficient and had only begun to talk at $8 \frac{1}{2}$ years; he could not be further examined and was not, therefore, included in the investigation. One other mentally deficient child was seen in his own home; he, too, was in the 'asphyxia' group, but could not be examined and is not included in the investigation. From these few data no significance can be attached to the fact that all three children experienced asphyxia neonatorum at birth. More data would be required to examine the association, if any, between the birth condition and athetosis or mental deficiency.

Finally, special attention was paid during the examinations to the possibility of chronic lower respiratory infection, to see whether there was any suggestion that poor respiratory movement in the first few days of life might predispose to chronic respiratory disorder in later life. Persistent adventitious sounds (not associated with any apparent acute infection at the time of examination) were found in $10 \%$ of the ' asphyxia' group and in $13 \%$ of the controls. The difference could easily have arisen by chance $\left(\chi^{2}=0 \cdot 12\right.$, degrees of freedom $=1$, and $0.8>P>0 \cdot 7)$. These data thus lend no support to the hypothesis suggested above. It was not possible to assess the severity of the chest signs by any precise standard, and no more detailed comparison has therefore been attempted.

\section{Summary}

An attempt has been made to examine the present physical and mental condition of all children born during the years 1938 to 1941 in the Royal Maternity Hospital, Belfast, with severe asphyxia neonatorum (89 children) and of a group of unselected controls (178 children).

Of the total 267 children, 195, or $73 \%$, were ultimately examined. A comparison of numerous known conditions extracted from the birth records between the examined and the unexamined groups of children did not reveal any important significant differences. It seems unlikely, therefore, that the loss of $27 \%$ of the original subjects would affect the aim of the enquiry, the assessment of the remote prognosis of asphyxia neonatorum.

After due allowance for relevant concomitant factors, with only one exception, no significant difference has been found in the average physical measurements (height, weight, inspired chest measurement and chest expansion) or in haemoglobin levels or in intelligence distributions (as assessed from Raven's matrices) between the 'asphyxia' and the control group. The exception occurred in the comparison of mean chest measurements of first born males: the mean for the 'asphyxia' group was just significantly less than that for the control group.

A brief résumé of other investigations on this subject has been given. Contrary to the general impression gained from most other work, the present data and analysis give no support for the hypothesis that asphyxia neonatorum is a common cause of later mental or physical retardation. One investigation (McPhail and Hall, 1941) carried out on similar lines to the present enquiry led to similar results with reference to intelligence rating.

We are indebted to the staff of the Royal Maternity Hospital, Belfast, for access to the birth records, and to Dr. G. Seth (lecturer in psychology, the Queen's University of Belfast) for advice on the technique of intelligence testing. Thanks are due to Mr. J. D. Merrett, of the Department of Social and Preventive Medicine, the Queen's University of Belfast, for considerable assistance in the statistical analysis.

A feature of the survey was the very willing cooperation of the majority of parents, who cheerfully gave up two or three hours to attend the examination sessions. Without their support and interest the present survey could not have been undertaken. 


\section{REFERENCES}

Asher, C., and Roberts, J. A. F. (1949). Brit. J. soc. Med., 3, 56.

Courville, C. B., and Marsh, C. (1944). Bull. Los Angeles neurol. Soc., 9, 121.

Darke, R. A. (1944). J. Pediat., 24, 148.

Despert, J. L. (1946). Nerv. Child, 5, 8.

Evans, P. R. (1948). Archives of Disease in Childhood, 23, 213.

Fisher, R. A. (1946). ' Statistical Methods for Research Workers,' 10th ed. London and Edinburgh.

Galloway, C. E. (1938). J. Amer. med. Ass., 111, 1269.

Gibson, Q. H., and Harrison, D. C. (1945), Biochem. J., 39, 490.

Illingworth, R. S., Harvey, C. C., and Shan-Yah Gin (1949). Lancet, 2, 598.

McPhail, F. L., and Hall, E. L. (1941). Amer. J. Obstet. Gynec., 42, 686.
Preston, M. I. (1945). J. Pediat., 26, 353.

Raven, J. C. (1938). ' 'Progressive Matrices.' London. (1947). 'Progressive Matrices.' London.

- (1948). Brit. J. Psychol., 39, 12.

Rosenfeld, G. B., and Bradley, C. (1948). Pediatrics, 2, 74.

Schreiber, F. (1938). J. Amer. med. Ass., 111, 1263. (1943). J. Exceptional Child, 9, 227.

Smith, C. A. (1948). Advances in Pediatrics, 3. New York.

Snedecor, G. W. (1946). ' 'Statistical Methods,' 4th ed. Iowa.

Stevenson, S. S. (1948). Pediatrics, 2, 154.

Windle, W. F. (1944). Psychosom. Med., 6, 155. and Becker, R. F. (1943). Amer. J. Obstet. Gynec., 45, 183. and Weil, A. (1944). J. Neuropath. exp. Neurol., 3, 224. 